\title{
Correlation between maternal hemoglobin and serum transferrin receptor with lactoferrin concentration in breastfeeding mothers
}

\author{
MOHAMMAD ZEN RAHFILUDIN ${ }^{A-E}$, DINA RAHAYUNING PANGESTUTIB, F, G, \\ ORCID ID: 0000-0003-2290-0395 ORCID ID: 0000-0003-4421-9701 \\ SUYATNO SUYATNO ${ }^{B, F}$, SUROTO SUROTOC, D \\ ORCID ID: 0000-0001-7328-089X ORCID ID: 0000-0001-6333-4508
}

Faculty of Public Health, Diponegoro University, Semarang, Indonesia

A - Study Design, B - Data Collection, C - Statistical Analysis, D - Data Interpretation, E - Manuscript Preparation, F - Literature Search, G - Funds Collection

Summary Background. Human milk is rich in both nutrient and non-nutrient content which leads to many benefits for the growth and development of children's and mothers' bodies. Lactoferrin is one of the main proteins contained in human milk, and the factors that affect its concentration are important to comprehend.

Objectives. This study aimed to analyze the correlation between hemoglobin and serum transferrin receptor with lactoferrin concentration in human milk.

Material and methods. This cross-sectional study was conducted from September to November 2017. The subjects were 79 pregnant mothers in three working areas of the primary health centers in Semarang City, Indonesia. Hemoglobin and serum transferrin receptor data was obtained from blood during the third trimester of pregnancy, while lactoferrin concentration was measured in milk after delivery. Hemoglobin concentration was measured using cyanmethemoglobin, serum transferrin receptor concentration using enzyme-linked immunosorbent assay (ELISA), and lactoferrin concentration using a human lactoferrin ELISA. Data analysis was performed with Spearman's rank correlation coefficient using SPSS version 23.

Results. There was no correlation between maternal hemoglobin and lactoferrin concentration $(p=0.636)$. There was also no correlation between serum transferrin receptor and lactoferrin concentration $(p=0.688)$. Hemoglobin and serum transferrin receptors did not affect the concentration of lactoferrin in breastfeeding mothers.

Conclusions. The mechanism of lactoferrin homeostasis in human milk is still not completely understood. Further studies on this are important in order to promote a better quality of health for mothers and their children.

Key words: human milk, lactoferrin, hemoglobin, transferrin receptors.

Rahfiludin MZ, Pangestuti DR, Suyatno S, Suroto S. Correlation between maternal hemoglobin and serum transferrin receptor with lactoferrin concentration in breastfeeding mothers. Fam Med Prim Care Rev 2021; 23(4): 465-469, doi: https://doi.org/10.5114/ fmpcr.2021.110364.

\section{Background}

Over the years, many studies have proved that breastfeeding is important for both mothers and children. Breastfeeding is associated with lower infectious morbidity and mortality, fewer dental malocclusions and higher intelligence in children. Growing evidence also suggests that breastfeeding might protect against overweight and diabetes later in life. Mothers who breastfeed their children receive many benefits, such as preventing breast cancer, improved birth spacing and, possibly, a reduced risk of diabetes and ovarian cancer [1]. A study in Croatia even found that breastfeeding can lower the risk of depression in postpartum mothers [2]. Based on World Health Organization (WHO) and United Nations Children's Fund (UNICEF) recommendations, children should be exclusively breastfed for the first six months; breastfeeding should then continue for up to two years, while also providing the infant with nutritionally adequate and safe complementary food [3].

One of the factors that has a role in the benefits of breastfeeding is the content of human milk, which is rich in nutrients. Human milk has many antioxidant, antibacterial, prebiotic, probiotic and immune-boosting properties in addition to nutrients [4]. It contains biologically active components, non-protein nitrogen, immunoglobulin, lipids, carbohydrates and over 400 different proteins, in which the concentration differs according to the child's age and other characteristics to reflect their need [5]. Among the nutrients contained in human milk is a protein that is beneficial for infants' health, namely lactoferrin. Lactoferrin is one of the main whey proteins in human milk, with significant quantities [6]. Lactoferrin is a single polypeptide chain glycoprotein with a molecular weight of around $78 \mathrm{kDa}$ and consists of 691 amino acids. Based on its structure, lactoferrin has a similar concentration to serum transferrin receptor (STfR) of $60 \%$. Lactoferrin is present in higher concentrations in milk and colostrum, as well as many other secretions, like tears, saliva, urine and gastric fluid. Meanwhile, in plasma or serum and whole blood, lactoferrin concentration is low, varying from 0.02 $\mu \mathrm{g} / \mathrm{ml}$ to $1.52 \mu \mathrm{g} / \mathrm{ml}$. Pregnancy and the menstrual cycle affect lactoferrin concentration in plasma. On the contrary, excessive iron intake, tumor growth, infection and inflammation increases lactoferrin concentration [7]. Lactoferrin has antimicrobial, antiinflammatory and anti-carcinogenic activities, highlighting the therapeutic values of this multifunctional protein [8]. In infants, lactoferrin may impact gut health and gut-immune development and functioning. It also decreases the risk of lower respiratory tract illness and decreases the burden of colonization by some parasites in underdeveloped settings [9]. In terms of nutritional function, lactoferrin transports iron and detoxifies free 
radicals in biological fluids so that it is beneficial for people with iron deficiency [8].

Iron deficiency commonly occurs during pregnancy due to the increase in iron demand. It develops slowly over time and may not be symptomatic or clinically obvious. Once iron stores are completely depleted, iron accessibility to the tissues declines, leading to symptomatic anemia [10]. Since 2011, the global prevalence of anemia among pregnant mothers has shown an increasing trend every year. In 2016, the data showed that up to $40.1 \%$ of pregnant women suffer from anemia [11]. According to Indonesia Basic Health Research 2018, the prevalence of anemic pregnant mothers increased over the previous five years from $37.1 \%$ in 2013 to $48.9 \%$ in 2018 [12].

Iron Deficiency Anemia (IDA) is harmful during pregnancy, as it is associated with perinatal outcomes, including premature labor, intrauterine growth retardation, low birth weight, birth asphyxia and neonatal anemia [13]. Breastfeeding mothers can also be negatively affected by IDA, considering that maternal nutritional status is closely associated with the quality of human milk; therefore, impairment in human milk content may occur due to maternal anemia. Maternal anemia can alter the quality of human milk both in the nutrient and non-nutrient content [14].

The WHO and Centers for Disease Control and Prevention (CDC) Technical Consultation have established hemoglobin ( $\mathrm{Hb})$ and sTfR concentration as an indicator of iron status in the population. $\mathrm{Hb}$ concentration is a measure of anemia, while sTfR, which is derived mostly from developing red blood cells, reflects the balance between cellular iron requirements and iron supply, and it is a marker of the severity of iron insufficiency only when iron stores have been exhausted, provided that there are no other causes of abnormal erythropoiesis [15].

A study on anemic and non-anemic breastfeeding mothers found that even though $\mathrm{Hb}$ concentration increases after iron supplementation, lactoferrin concentration in both groups was similar at the end of 30 days of supplementation [16]. From our previous study, we know that mothers with better nutritional status have higher lactoferrin concentration in their milk [17]. However, there have been few studies related to maternal iron status and its effect on the quality of human milk, and this is poorly understood. Considering that lactoferrin is the main protein of human milk and has many benefits for an infant's growth and development during the breastfeeding period, this study aims to analyze its correlation with iron status.

\section{Objectives}

This study aimed to analyze the correlation between $\mathrm{Hb}$ and sTfR concentration during pregnancy with the lactoferrin concentration of breastfeeding mothers.

\section{Material and methods}

\section{Study design}

This was a quantitative study with an analytical design and a cross-sectional approach.

\section{Setting}

The study was conducted for three months, from September to November 2017, in the working areas of the Kedungmundu, Bangetayu and Genuk primary health centers in Semarang City, Indonesia. The data for this study was collected in two periods. The first data collection was during the third trimester of pregnancy; this included data on subject characteristics, anthropometric measurements, nutrition intake and blood samples for $\mathrm{Hb}$ and STfR concentration analysis. The second data collection was after delivery, in which milk samples were collected for lactoferrin concentration analysis. All subjects participated in both stages of data collection.

\section{Participants}

The subjects were 79 pregnant mothers who were selected using purposive sampling. The sample size was determined with Slovin's formula. The inclusion criteria were willingness to participate in the study, giving birth in September 2017, breastfeeding mothers, having a singleton child, children born at a normal weight $(>2,500 \mathrm{~g})$ and having children without abnormalities that made suckling difficult.

\section{Variables}

The variables assessed in this study were maternal hemoglobin, serum transferrin receptor and lactoferrin concentration.

\section{Data sources/ Measurement}

Data on subject characteristics, such as education level and occupation, was obtained through interviews with the subjects. Education level was categorized into two groups: (a) primary, which was six years in elementary school and three years in junior high school; and (b) secondary or higher, which was three years in senior high school and about three to four years at college.

Nutritional intake data was obtained using a 24-hour recall method for two non-consecutive days, with pictures of food to help subjects determine the food portions they consumed. Food intake was recorded in the form of household portions, such as tablespoons, teaspoons, cups, etc. This was then converted into grams and analyzed using NutriSurvey software to calculate the nutrition intake. The data was then compared with the Indonesian Recommended Dietary Allowance (RDA), which is based on the 2019 Republic of Indonesia Ministry of Health Regulation No. 28 [18]. The anthropometric data used in this study was mid-upper arm circumference (MUAC) measured with an MUAC tape. Subjects with an MUAC of less than $23.5 \mathrm{~cm}$ were categorized as at risk of Chronic Energy Deficiency (CEM) [19].

For the analysis of $\mathrm{Hb}$ and sTfR, about $5 \mathrm{~mL}$ of venous blood was taken from the subjects once in the morning between 8 am and $10 \mathrm{am}$. $\mathrm{Hb}$ concentration was measured using cyanmethemoglobin, while sTfR was measured using a Quantikine IVD Human STfR Immunoassay (R\&D Systems, Minneapolis, MN, USA) with an Enzyme-Linked Immunosorbent Assay (ELISA) Reader 680 using a quantitative sandwich technique. Subjects were categorized as anemic if $\mathrm{Hb}$ concentration was below $11 \mathrm{~g} / \mathrm{dL}$ [19] and STfR concentration was greater than or equal to $21.0 \mathrm{nmol} / \mathrm{L}$ [20].

For lactoferrin analysis, the subjects' milk was collected door to door. About $5 \mathrm{~mL}$ was taken with a sterilized human milk pump and placed in a sterile glass bottle. Samples were put inside a refrigerator during the visit and further stored in a freezer at $-20^{\circ} \mathrm{C}$. Storage time both in the refrigerator and the freezer was recorded and considered during analysis to ensure it did not affect lactoferrin concentration. Data on milk collection time was also recorded and analyzed to avoid diurnal variation during milk collection. The lactation stage of the breastfeeding mothers was confirmed by the day breastfeeding began and the infants' age at time of collection. Analysis of lactoferrin concentration in human milk was carried out using a Human Lactoferrin ELISA (Biovendor-Laboratorni medivina a.s, Karasek, Czech Republic) with a detection limit of 1.1 nanograms $/ \mathrm{ml}$.

\section{Statistical methods}

Data was analyzed using SPSS software version 23. The normality of the data was assessed using the Kolmogorov-Smirnov test. Data with a normal distribution was analyzed using Pearson's product moment test, while Spearman's rank correlation coefficient was used to assess the correlation of variables if the data distribution was not normal.

\section{Ethical consideration}

Ethical clearance to conduct this study (No. 252/EC/FKM/ /2016) was obtained from the Commission of Ethics of Medical 
and Public Health Research of the Faculty of Public Health, Diponegoro University, Semarang, Indonesia. All subjects provided written informed consent before inclusion.

\section{Results}

The mean age of the subjects at the time of study was 27.95 \pm 5.08 years. During the third trimester of pregnancy, mean MUAC was $25.0 \mathrm{~cm}$. The majority of breastfeeding mothers had secondary or higher education levels $(68.4 \%)$, were housewives $(65.8 \%)$ and had normal nutritional status, as indicated by the MUAC (98.7\%). The distribution of lactation stage among breastfeeding mothers was almost even: colostrum (35.4\%), transition (30.4\%) and mature (34.2\%) (Table 1).

\begin{tabular}{|l|l|}
\hline \multicolumn{2}{|l|}{ Table 1. Distribution of characteristics of subjects } \\
\hline Variables & Value \\
\hline Age (years) & $27.95 \pm 5.08$ \\
\hline MUAC at third trimester $(\mathrm{cm})$ & $25.0(19.8-35.0)$ \\
\hline $\begin{array}{l}\text { Level of education } \\
\text { primary } \\
\text { secondary or higher }\end{array}$ & $25(31.6 \%)$ \\
\hline $\begin{array}{l}\text { Occupation } \\
\text { housewife }\end{array}$ & $54(68.4 \%)$ \\
laborer & $52(65.8 \%)$ \\
entrepreneur & $8(10.1 \%)$ \\
private employee & $7(8.9 \%)$ \\
civil servant & $4(5.1 \%)$ \\
\hline Nutritional status & $8(10.1 \%)$ \\
CEM & \\
normal & $1(1.3 \%)$ \\
\hline Lactation stage & $78(98.7 \%)$ \\
colostrum (g/L) & \\
transition $(\mathrm{g} / \mathrm{L})$ & $28(35.4 \%)$ \\
mature (g/L) & $24(30.4 \%)$ \\
\hline
\end{tabular}

${ }^{\mathrm{a}}$ Mid-upper arm circumference, ${ }^{\mathrm{b}}$ chronic energy deficiency.

\begin{tabular}{|c|c|c|c|}
\hline Variables & Value & Min & Max \\
\hline Energy (kcal) & $2,595.58 \pm 401.88$ & & \\
\hline Carbohydrate (g) & $283.98 \pm 60.49$ & & \\
\hline Protein (g) & $113.81 \pm 23.65$ & & \\
\hline Dietary cholesterol (mg) & 377.0 & 0.0 & $1,314.0$ \\
\hline Fat (g) & $77.42 \pm 26.61$ & & \\
\hline Dietary fiber (g) & 37.2 & 31.9 & 51.0 \\
\hline Vitamin A (RE) & 967.0 & 49.0 & $9,462.0$ \\
\hline Thiamin (mg) & 1.8 & 1.1 & 2.9 \\
\hline Riboflavin (mg) & $2.13 \pm 1.29$ & & \\
\hline Niacin (mg) & $12.01 \pm 4.66$ & & \\
\hline Vitamin $B_{6}(\mathrm{mg})$ & 1.4 & 0.6 & 4.6 \\
\hline Folic acid $(\mu \mathrm{g})$ & 716.0 & 545.0 & $1,346.0$ \\
\hline Vitamin $B_{12}(\mu \mathrm{g})$ & 6.1 & 0.1 & 65.4 \\
\hline Vitamin C (mg) & 93.0 & 51.1 & 388.0 \\
\hline Vitamin $E(\mu \mathrm{g})$ & 15.0 & 15.0 & 16.2 \\
\hline Iron (mg) & 40.5 & 26.3 & 47.3 \\
\hline Zinc (mg) & $20.09 \pm 3.15$ & & \\
\hline
\end{tabular}

All subjects met the nutritional need for pregnant women based on the Indonesian RDA (Table 2). Nutritional intake that had a significant relationship to $\mathrm{Hb}$ concentration was protein, dietary cholesterol, fat, all types of vitamin B (thiamin, riboflavin, niacin, vitamin $B_{6}$, folic acid and vitamin $B_{12}$ ), vitamin $C$, iron and zinc. STfR concentration was significantly related to the intake of thiamin, niacin, folic acid, vitamin $\mathrm{C}$ and iron. In every nutritional intake studied, Spearman's rank correlation coefficient found no correlation with lactoferrin concentration (Table 3).

\begin{tabular}{|c|c|c|c|}
\hline \multirow[t]{2}{*}{ Variables } & \multicolumn{3}{|l|}{$p$} \\
\hline & $\begin{array}{l}\text { Hemoglobin } \\
\text { (g/dL) }\end{array}$ & $\begin{array}{l}\text { Serum } \\
\text { transferrin } \\
\text { receptor } \\
\text { (nmol/L) }\end{array}$ & $\begin{array}{l}\text { Lactoferrin } \\
(\mathrm{g} / \mathrm{L})\end{array}$ \\
\hline Energy (kcal) & 0.001 & 0.125 & 0.783 \\
\hline Carbohydrate (g) & 0.073 & 0.692 & 0.405 \\
\hline Protein (g) & 0.002 & 0.072 & 0.848 \\
\hline $\begin{array}{l}\text { Dietary cholesterol } \\
\text { (mg) }\end{array}$ & 0.001 & 0.235 & 0.665 \\
\hline Fat (g) & 0.009 & 0.516 & 0.342 \\
\hline Dietary fiber (g) & 0.517 & 0.929 & 0.708 \\
\hline Vitamin A (RE) & 0.078 & 0.312 & 0.278 \\
\hline Thiamin (mg) & 0.002 & 0.036 & 0.952 \\
\hline Riboflavin (mg) & 0.012 & 0.098 & 0.986 \\
\hline Niacin (mg) & 0.022 & 0.046 & 0.099 \\
\hline Vitamin $B_{6}(\mathrm{mg})$ & 0.021 & 0.171 & 0.599 \\
\hline Folic acid $(\mu \mathrm{g})$ & 0.001 & 0.024 & 0.768 \\
\hline Vitamin $B_{12}(\mu \mathrm{g})$ & 0.015 & 0.192 & 0.750 \\
\hline Vitamin C (mg) & 0.001 & 0.001 & 0.969 \\
\hline Vitamin E ( $\mu \mathrm{g})$ & 0.337 & 0.133 & 0.701 \\
\hline Iron (mg) & 0.001 & 0.001 & 0.443 \\
\hline Zinc (mg) & 0.001 & 0.207 & 0.460 \\
\hline
\end{tabular}

The mothers did not suffer from anemia, which was shown through an $\mathrm{Hb}$ concentration above $11 \mathrm{~g} / \mathrm{dL}$ and sTfR concentration below $21.0 \mathrm{nmol} / \mathrm{L}$. The median lactoferrin concentration in human milk was $1.52(0.38-2.94) \mathrm{g} / \mathrm{L}$ (Table 4). There was no correlation between both $\mathrm{Hb}$ and STfR concentration with lactoferrin concentration of breastfeeding mothers (Table 5). However, $\mathrm{Hb}$ and $\mathrm{STfR}$ concentration showed a significant inverse correlation ( $p=0.001, r=-0.438)$.

\begin{tabular}{|c|c|c|c|}
\hline Variables & Median & Min & Max \\
\hline Hemoglobin (g/dL) & 11.3 & 8.9 & 14.3 \\
\hline $\begin{array}{l}\text { Serum transferrin receptor } \\
\text { (nmol/L) }\end{array}$ & 15.06 & 8.6 & 34.9 \\
\hline Lactoferrin $(\mathrm{g} / \mathrm{L})$ & 1.52 & 0.38 & 2.94 \\
\hline
\end{tabular}

Table 5. Correlation between maternal hemoglobin and serum transferrin receptor with lactoferrin concentration of breastfeeding mothers

Variables Lactoferrin concentration $(\mathrm{g} / \mathrm{L})$

\begin{tabular}{|l|l|l|}
\cline { 2 - 3 } & $\boldsymbol{R}$ & $\boldsymbol{P}$ \\
\hline Hemoglobin $(\mathrm{g} / \mathrm{dL})$ & 0.054 & 0.636 \\
\hline Serum transferrin receptor $(\mathrm{nmol} / \mathrm{L})$ & 0.046 & 0.686 \\
\hline
\end{tabular}

\section{Discussion}

Based on the Indonesian RDA, the nutritional intake of pregnant mothers during their third trimester was adequate. 
This was reflected in the MUAC, which was equal to or more than $23.5 \mathrm{~cm}$ in the majority of subjects. The median maternal $\mathrm{Hb}$ and sTfR showed that mothers did not have anemia, which could be a result of adequate iron intake, as well as other important nutrients that enhance iron absorption, such as vitamin $C$, vitamin $B_{12}$ and folic acid. Vitamin $C$ or ascorbic acid overcome the negative effect of iron-absorption inhibitors, such as phytate, polyphenols, calcium and proteins in milk products, and will increase the absorption of both native and fortification iron [21]. Meanwhile, vitamin $B_{12}$ and folic acid play an important role in the formation of red blood cells [22].

Maternal iron intake was significantly correlated to both $\mathrm{Hb}$ and STfR concentration. A study of breastfeeding mothers in Mexico showed that iron supplementation improved maternal $\mathrm{Hb}$ and STfR concentration [23] Mexico. $\mathrm{Hb}$ and STfR were found to have an inverse correlation. This can be interpreted that, in the case of anemia, $\mathrm{Hb}$ concentration became lower, while sTfR concentration rose. This result was supported by other studies in which $\mathrm{Hb}$ and STfR were negatively correlated $[24,25]$.

In the present study, lactoferrin concentration was found to be lower compared to mean lactoferrin concentration in several countries in Asia, namely Bangladesh $(5.72 \mathrm{~g} / \mathrm{L})$, India (3.71 $\mathrm{g} / \mathrm{L})$, Japan $(4.17 \mathrm{~g} / \mathrm{L}$ ) and Thailand ( $2.27 \mathrm{~g} / \mathrm{L}$ ) [26]. However, the concentration was in a similar range as China, which varied from $0.99 \mathrm{~g} / \mathrm{L}$ to $1.91 \mathrm{~g} / \mathrm{L}$ across its 11 provinces [27].

Regardless of the adequate nutritional intake of mothers, this was not associated with lactoferrin concentration. Consistent with this result, Cai et al. found no significant correlation between lactoferrin concentration in mature human milk with the various food intake of mothers [28]. Several studies also specifically reported that maternal protein intake did not affect lactoferrin content in human milk [27-29]. Therefore, consumption of food sources of protein such as meat, soy or milk was not necessarily associated with lactoferrin concentration [27]. This was likely due to the synthesis from maternal stores or body tissues when nutrients in milk were insufficient to maintain the balance of milk content [30].

In our previous study, we found that maternal nutritional status was a predictor of lactoferrin concentration in human milk [17], but this was evidently not the case for maternal iron status. Although $\mathrm{Hb}$ and STfR concentration met the standard for pregnant mothers, lactoferrin concentration was low, and they were not significantly correlated. Another study supported this result, which found that lactoferrin concentration in human milk did not depend on maternal iron status or iron supplementation [26]. Zavaleta et al. reported no correlation between maternal iron status and lactoferrin concentration in human milk at birth and during early lactation. Their study was conducted on both anemic and non-anemic breastfeeding mothers and used the $\mathrm{Hb}$ and hematocrit value to determine anemic status [16]. In India, a study on non-anemic and anemic breastfeeding mothers found that maternal $\mathrm{Hb}$ did not correlate with lactoferrin concentration in human milk on the first day, 14 weeks and six months after delivery [31].

A study in Brazil found that total protein levels in human milk were higher in anemic mothers regardless of their lactation stage (colostrum, transition, mature) [32]. Since lactoferrin is the main whey protein in human milk, and all mothers in the present study were non-anemic, we assumed this might be the cause of the low concentration of lactoferrin. Nevertheless, further studies are needed to explain the mechanism.

\section{Conclusions}

Maternal iron status, as indicated by $\mathrm{Hb}$ and STfR concentration, did not affect lactoferrin concentration in human milk. However, the mechanism of milk lactoferrin homeostasis is not completely understood. Thus, further studies are needed to help promote better health for mothers and their children. A limitation of this study was that data on nutritional intake with the 24-hour recall method might not represent the long-term dietary habits of the subjects. Moreover, there was a possibility that the subjects could not remember all the food they consumed for the day, which would lead to an inaccurate data record.

Acknowledgments. This study was approved by the Commission of Ethics of Medical and Public Health Research of the Faculty of Public Health, Diponegoro University, Semarang (No. 252/EC/FKM/2016). Financial support was provided by the Directorate of Community Nutrition from the Ministry of Health, Republic of Indonesia, under grant number HK.03.01/V/365/2017.

Source of funding: This work was financed by the Directorate of Community Nutrition from the Ministry of Health, Republic of Indonesia. Conflicts of interest: The authors declare no conflicts of interest.

\section{References}

1. Victora CG, Bahl R, Barros AJD, et al. Breastfeeding in the 21st century: epidemiology, mechanisms, and lifelong effect. Lancet 2016; 387: 475-490.

2. Mikšić Š, Uglešić B, Jakab J, et al. Positive effect of breastfeeding on child development, anxiety, and postpartum depression. Int J Environ Res Public Health 2020; 17(8): 2725, doi: 10.3390/ijerph17082725.

3. World Health Organization, UNICEF. Global strategy for infant and young child feeding. Geneva: WHO; 2003.

4. Eglash A, Simon L. ABM Clinical Protocol \#8: Human milk storage information for home use for full-term infants, revised 2017. Breastfeed Med 2017; 12: 390-395.

5. Andreas NJ, Kampmann B, Mehring Le-Doare K. Human breast milk: a review on its composition and bioactivity. Early Hum Dev 2015; 91: 629-635.

6. Mosca F, Giannì ML. Human milk: composition and health benefits. Pediatr Med Chir 2017; 39 : 155.

7. Taqi T, Fatima Qazi A, Qazi S, et al. Correlation of lactoferrin levels in breast milk with maternal haemoglobin percentage among lactating women of low and high socioeconomic status. Pak J Physiol 2017; 13: 30-33.

8. Wang B, Timilsena YP, Blanch E, et al. Lactoferrin: structure, function, denaturation and digestion. Crit Rev Food Sci Nutr 2019; 59(4): 580-596, doi: 10.1080/10408398.2017.1381583.

9. Manzoni P. Clinical benefits of lactoferrin for infants and children. J Pediatr 2016; 173: S43-S52.

10. Abu-Ouf NM, Jan MM. The impact of maternal iron deficiency and iron deficiency anemia on child's health. Saudi Med J 2015; 36: 146-149.

11. World Health Organization. Prevalence of Anemia Among Pregnant Women (2016) [cited 11.05.2020]. Available from URL: https:// data.worldbank.org/indicator/SH.PRG.ANEM.

12. National Institute of Health Research and Development, Ministry of Health Republic of Indonesia. Main Result of Basic Health Research 2018. Jakarta: Ministry of Health Republic of Indonesia; 2018.

13. Renzo GC Di, Spano F, Giardina I, et al. Iron deficiency anemia in pregnancy. Women's Heal 2015; 11: 891-900. 
14. Fujita M, Paredes Ruvalcaba N, Wander K, et al. Buffered or impaired: maternal anemia, inflammation and breast milk macronutrients in northern Kenya. Am J Phys Anthropol 2019; 168: 329-339.

15. World Health Organization/Centers for Disease Control and Prevention Technical Consultation. Assessing the iron status of population. 2nd ed. Geneva: WHO; 2004.

16. Zavaleta N, Nombera J, Rojas R, et al. Iron and lactoferrin in milk of anemic mothers given iron supplements. Nutr Res 1995; 15(5): 681-690, doi: 10.1016/0271-5317(95)00035-H.

17. Rahfiludin MZ, Pangestuti DR. Lactoferrin association with maternal nutritional status and lactation stages. Curr Res Nutr Food Sci J 2020; 8: 174-181.

18. Ministry of Health Republic of Indonesia. The 2019 Republic of Indonesia Ministry of Health Regulation No. 28 Regarding Indonesian Recommended Dietary Allowance. Jakarta: Ministry of Health Republic of Indonesia; 2019.

19. Par'i HM, Wiyono S, Harjatmo TP. Assessment of nutritional status. Jakarta: Ministry of Health of Republic of Indonesia; 2017.

20. Khambalia $\mathrm{AZ}$, Collins $\mathrm{CE}$, Roberts $\mathrm{CL}$, et al. Iron deficiency in early pregnancy using serum ferritin and soluble transferrin receptor concentrations are associated with pregnancy and birth outcomes. Eur J Clin Nutr 2016; 70: 358-363.

21. Abbaspour N, Hurrell R, Kelishadi R. Review on iron and its importance for human health. J Res Med Sci 2014; $19: 164-174$.

22. Bhardwaj A, Kumar D, Raina SK, et al. Rapid assessment for coexistence of vitamin $B_{12}$ and iron deficiency anemia among adolescent males and females in Northern Himalayan State of India. Anemia 2013; 2013: 959605, doi: 10.1155/2013/959605.

23. Khambalia A, Latulippe ME, Campos C, et al. Milk folate secretion is not impaired during iron deficiency in humans. J Nutr 2006; 136: 2617-2624.

24. Yokus O, Yilmaz B, Albayrak M, et al. The significance of serum transferrin receptor levels in the diagnosis of the coexistence of anemia of chronic disease and iron deficiency anemia. Eurasian J Med 2011; 43: 9-12.

25. Yoon SH, Kim DS, Yu ST, et al. The usefulness of soluble transferrin receptor in the diagnosis and treatment of iron deficiency anemia in children. Korean J Pediatr 2015; 58: 15-19.

26. Rai D, Adelman AS, Zhuang W, et al. Longitudinal changes in lactoferrin concentrations in human milk: a global systematic review. Crit Rev Food Sci Nutr 2014; 54: 1539-1547.

27. Yang $Z$, Jiang $R$, Chen $Q$, et al. Concentration of lactoferrin in human milk and its variation during lactation in different Chinese populations. Nutrients 2018; 10: 1-10.

28. Cai X, Duan Y, Li Y, et al. Lactoferrin level in breast milk: a study of 248 samples from eight regions in China. Food Funct 2018; 9 : 4216-4222.

29. Motil KJ, Thotathuchery M, Bahar A, et al. Marginal dietary protein restriction reduced nonprotein nitrogen, but not protein nitrogen, components of human milk. J Am Coll Nutr 1995; 14: 184-191.

30. Institute of Medicine (US) Committee on Nutritional Status During Pregnancy and Lactation. Nutrition during lactation. Washington (DC): National Academies Press; 1991. Available from URL: https://www.ncbi.nlm.nih.gov/books/NBK235590/\#ddd00119.

31. Shashiraj AA, Faridi MMA, Singh O, et al. Mother's iron status, breastmilk iron and lactoferrin - are they related? Eur J Clin Nutr 2006; 60: 903-908.

32. França EL, Silva VA, Volpato RMJ, et al. Maternal anemia induces changes in immunological and nutritional components of breast milk. J Matern Neonatal Med 2013; 26: 1223-1227.

Tables: 5

Figures: 0

References: 32

Received: 16.07.2020

Reviewed: 31.07 .2020

Accepted: 04.02.2021

Address for correspondence:

Mohammad Zen Rahfiludin, PhD, Assoc. Prof.

Faculty of Public Health

Diponegoro University

Jl. Prof Sudharto SH

Kampus Undip Tembalang

Semarang

Indonesia 50275

Tel.: +62 8122889745

E-mail: rahfiludin@yahoo.com 